\title{
FALLING WEIGHT IMPACT TEST OF A NEW-TYPE FLEXIBLE ROCK-SHED
}

\author{
Jianrong Yang ${ }^{12^{*}}$ - Yonghong Chen² - Zhiyu Zhang ${ }^{2}$ - Yunfei Luo ${ }^{3}$
}

\begin{abstract}
${ }^{1}$ State Key Laboratory Breeding Base of Mountain Bridge and Tunnel Engineering, Chongqing Jiaotong University, Chongqing 400074, China

${ }^{2}$ Department of Civil Engineering, Kunming University of Science and Technology, Kunming 650500, China

${ }^{3}$ Kunming Survey, Design and Research Institute Co. Ltd. of CREEC, Kunming 650200, China
\end{abstract}

\begin{tabular}{l} 
ARTICLE INFO \\
\hline Article history: \\
Received: 8.3 .2016$. \\
Received in revised form: 10.4 .2016$. \\
Accepted: 10.5 .2016$. \\
\hline Keywords: \\
Flexible rock-shed \\
Rockfall \\
Impact \\
Experimental study \\
Numerical simulation
\end{tabular}

\section{Introduction}

Rockfall is one of the major natural hazards that commonly occur in mountainous areas, which usually develops from steep slopes, initially unstable or disturbed by slope cutting and blasting, etc. It may result in severe consequences once it occurs, e.g. impassable roads or rail tracks,

\begin{abstract}
:
A new concept of a flexible rock-shed is presented for protection of the railway from falling rocks. The flexible rock-shed is made of flexible nets connected by specific spring spacer bars to an array of reinforced concrete portable frames which are linked by a longitudinal steel tube truss. To evaluate the performance of the flexible rock-shed, experimental and numerical studies are carried out in the present study. Impact tests are conducted on a full-scale partial model of the prototype structure when it is subjected to a falling block of $340 \mathrm{~kg}$. The impact time interval, maximum deflection of the flexible net, tensile forces in the supporting ropes, and axial strains of spring spacer bars are recorded. To further examine the dynamic behavior of the flexible rock-shed, numerical simulations are also carried out by using the explicit finite element code ANSYS/LS-DYNA. It is found that the numerical results coincide well with the experimental data and both the numerical and experimental studies reveal that the structure can withstand impact energy of $50 \mathrm{~kJ}$ with all the materials working in the elastic range. The structural details are improved and the basis for the design and construction of similar structures in the future is provided.
\end{abstract}

destroyed infrastructures, etc. [1] It is important to protect the engineering structures from the possible rock fall impact.

Different from highway requirements, the railway lines have a much higher standard on the protection level. The technique usually shelters the existing railways consisting in setting up, above the lines full covered sheds or opening cut tunnels in the

\footnotetext{
* Corresponding author. Tel.: +86 13078749433

E-mail address: 332970794@qq.com
} 
zone that is exposed to rock fall. Conventionally, the reinforced concrete structures are applied to the rock-sheds, in which concrete slabs covered with sand-gravel act as shock absorbers. The impact loads spread and transfer to the slabs, and frames underneath are effectively buffered by the cushion layers. Conventional reinforced concrete shed structures have large stiffness and good protection performance. However, the disadvantages of this protection technology are also quite obvious. For instance, the dead load of these protection structures demands massive foundations which are difficult and expensive to build because of the gradient of slopes and the frequently poor quality of bedrocks. Moreover, the removal of the fallen blocks, the replacements of the embankments are difficult and even impossible in some cases [2]. Furthermore, traffic disruption to existing railway is inevitable during construction. These disadvantages impede the application of these reinforced concrete rocksheds.

With the aim of making reinforced concrete rocksheds more powerful to dissipate impact energy and cost less, many innovative methods were introduced. Ikeda et al. [3] proposed a three layered absorbing system. Besides the cushion layer and reinforced concrete slab, a 0.5-1.0 m thick expanded polystyrol block was added as the bottom layer. The subsequent impact tests demonstrated that the improved design has the advantage of reducing the impact force on the slab. However, this proposed system remains difficult to be repaired after a damage. Mougin et al. [4] and Delhomme et al. [5, 6] developed a new rock-shed made of reinforced concrete slabs held up by specially designed supports that act as expendable fuses to absorb the kinetic energy of the falling rocks. The energy is dissipated directly into the reinforced concrete slab or into the fuse supports, and no longer into a cushion layer. This innovation significantly reduces the thickness of the slab and the total dead weight, which leads to savings on the foundations system. But the slab may suffer considerable damage after the high energy impacts.

Instead of using sand-gravel cushions, flexible barriers can be exploited as the buffer layer in flexible rock-sheds, which is lightweight and usually supported by steel structures underneath. These structures take advantage of the flexibility, high-strength and high-impact resistance of the flexible nets. Furthermore, easy processing and molding characteristics of metallic materials facilitate the nets to satisfy various structural forms with aesthetic advantages. Compared to the conventional rock-sheds, the flexible rock-sheds introduce no traffic interruption and cost less. Wang et al. [7, 8] and Shi et al. [9] carried out experimental and numerical analyses on the effectiveness of flexible rock-sheds. Testing results showed that part of the steel structure buckled and deflected seriously after impact, and the effectiveness of the flexible rock-sheds therefore decreases.

One the other hand, the transient impact analysis of the falling rocks on a flexible rock-shed is a very complex problem since the problem is governed by the dynamic characteristics of the structure and the status of movement of the projectiles. Moreover, the geometrical non-linearity and elastoplastic behavior of the steel nets even increase the difficulty of the problem. As a result, analytical investigation of the problem becomes quite complex and numerical methods are widely adopted. Previous studies (e.g. $[10,11])$ demonstrated the efficiency of using finite element modelling to evaluate the dynamic responses of flexible rock-sheds subjected to falling weights.

This paper proposes a new design concept by introducing appropriate energy dissipation devices into the flexible rock-sheds. The new flexible rockshed is made of flexible nets connected by specific spring spacer bars to the relatively rigid reinforced concrete frames linked by a longitudinal steel tube truss. The spring spacer bars serve as buffers to increase the flexibility and damping of the structure. The kinetic energy of falling rocks therefore can be significantly dissipated and the structural responses can be obviously reduced. To evaluate the performance of the proposed flexible rock-shed, experimental and numerical simulations are carried out and the results are reported in the present study.

\section{Flexible rock-shed design}

The Nankun railway crossing over the karst region in Yunnan province, China is taken as an example. Due to the influences of climatic seasonality, rock weathering and earthquakes, the potential of rock fall along this railway line is very high and urgent remediation is recommended. In view of the dense traffic condition of the railway line, the design scheme of the new shed structure is expected to be 
capable of reducing traffic disruption as much as possible to speed up the construction. According to the previous investigation of rock falls in this area, and also considering the economic factors, safety distance, and technical limitations, a new type of flexible rock-shed was proposed. This flexible rockshed was designed based on an impact energy level of $50 \mathrm{~kJ}$ and falling rocks with maximum mass of $340 \mathrm{~kg}$. Fig. 1 shows the design of the flexible rockshed. The flexible nets and the spring spacer bars, which connect the nets to the steel tube truss, compose the upper cushioning structure. The upper cushioning structure is supported by an array of reinforced concrete portable frames. The truss, whose members are connected with bolt sphere joints, is supported by rubber bearings laid on the reinforced concrete frames. When the rock-shed is impacted by the falling rocks, the kinetic energy of the falling rocks will be buffered and dissipated directly by the large deflection of the flexible nets and by the actuation of spring spacer bars, while the rest elements of the shed (the steel tube truss and reinforced concrete portable frames) are supposed to work within the elastic range. Moreover, an adequate distance of $2000 \mathrm{~mm}$ is reserved between the nets and the truss to avoid the possible collisions between the falling rocks and the truss. Fig. 2 shows a photo of the finalized rock-shed.

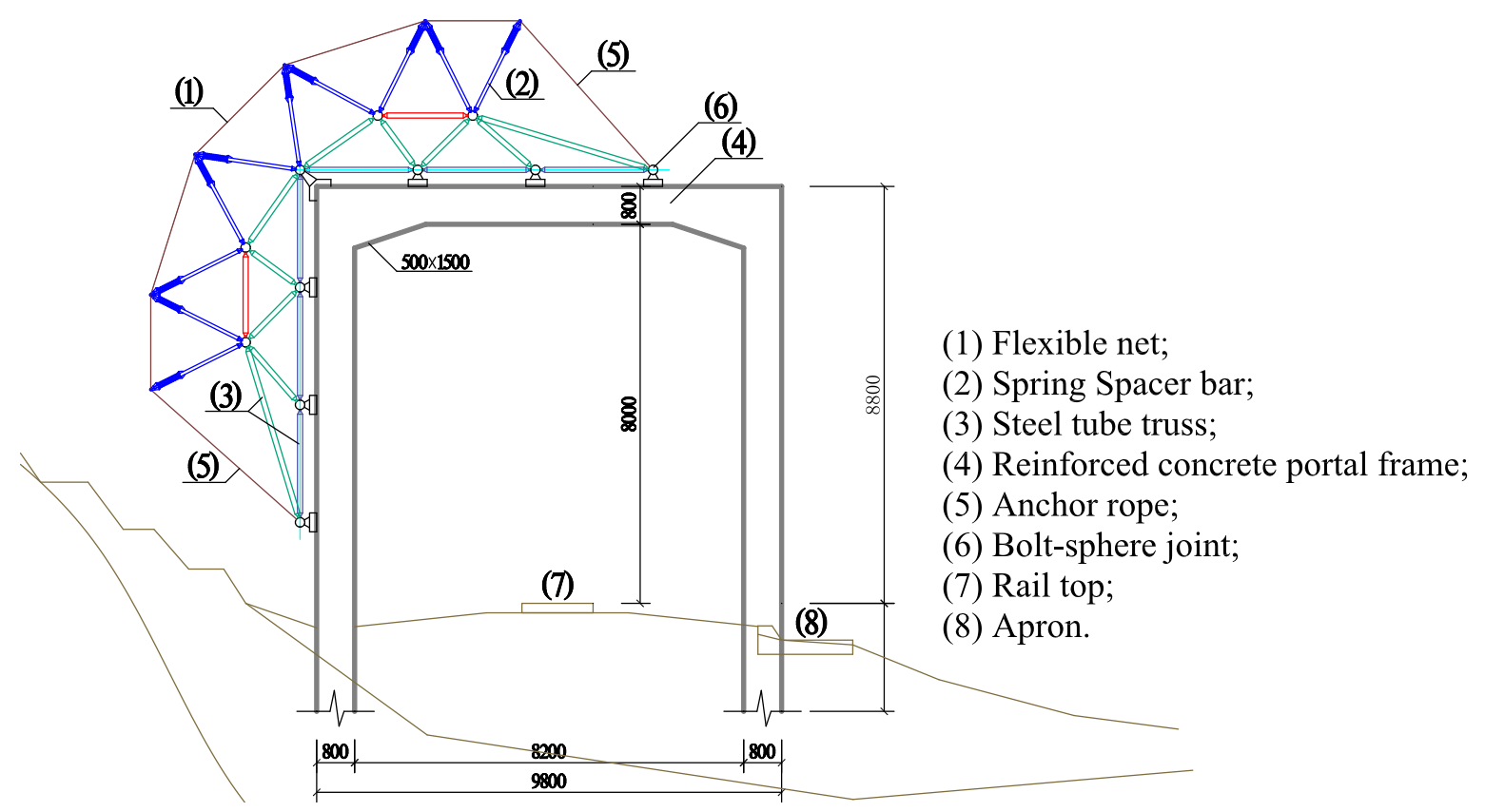

Figure 1.Flexible rock-shed design and dimensions (unit: $\mathrm{mm}$ )

Fig. 3 shows the details of the flexible nets. As it can be seen in the figure, the flexible net is made up of two overlaid nets: a ring net and a wire rope net. The ring net is composed of mutually connected ROCCO rings. Each ROCCO ring is manufactured from a steel wire of $3 \mathrm{~mm}$ in diameter which is evenly coiled seven times with inscribed circle diameter of $300 \mathrm{~mm}$ and fixed by three hoops. The wire rope net is made of steel wire ropes of $16 \mathrm{~mm}$ in diameter then forming wire meshes of 500 $\mathrm{mm} \times 500 \mathrm{~mm}$ each with special cross clip fixed in the cross nodes. Both the ring net and the wire rope net are connected to the support ropes (double rope with $31 \mathrm{~mm}$ in diameter for each) around by sewing ropes. They are supposed to directly bear the rock fall impact and buffer the kinetic energy by the large deformations. In order to hold the flexible net tight enough, tension should be applied to the support ropes, which render the spring spacer bars under compression.

To facilitate the replacement of the spring spacer bars when they are damaged, each spring spacer bar is made up of two socketed steel tubes with $68 \mathrm{~mm}$ and $50 \mathrm{~mm}$ in diameter and $8.5 \mathrm{~mm}$ and $9 \mathrm{~mm}$ in thickness respectively and a cylinder helical spring (Fig. 4). YB $35 \times 140 \times 720$ spring is selected following the Chinese GB/T 2089-2009 criteria [12] with spring stiffness $k=432 \mathrm{kN} / \mathrm{m}$, maximum load capacity $F n=71.16 \mathrm{kN}$ and maximum deformation $f n=165 \mathrm{~mm}$. 


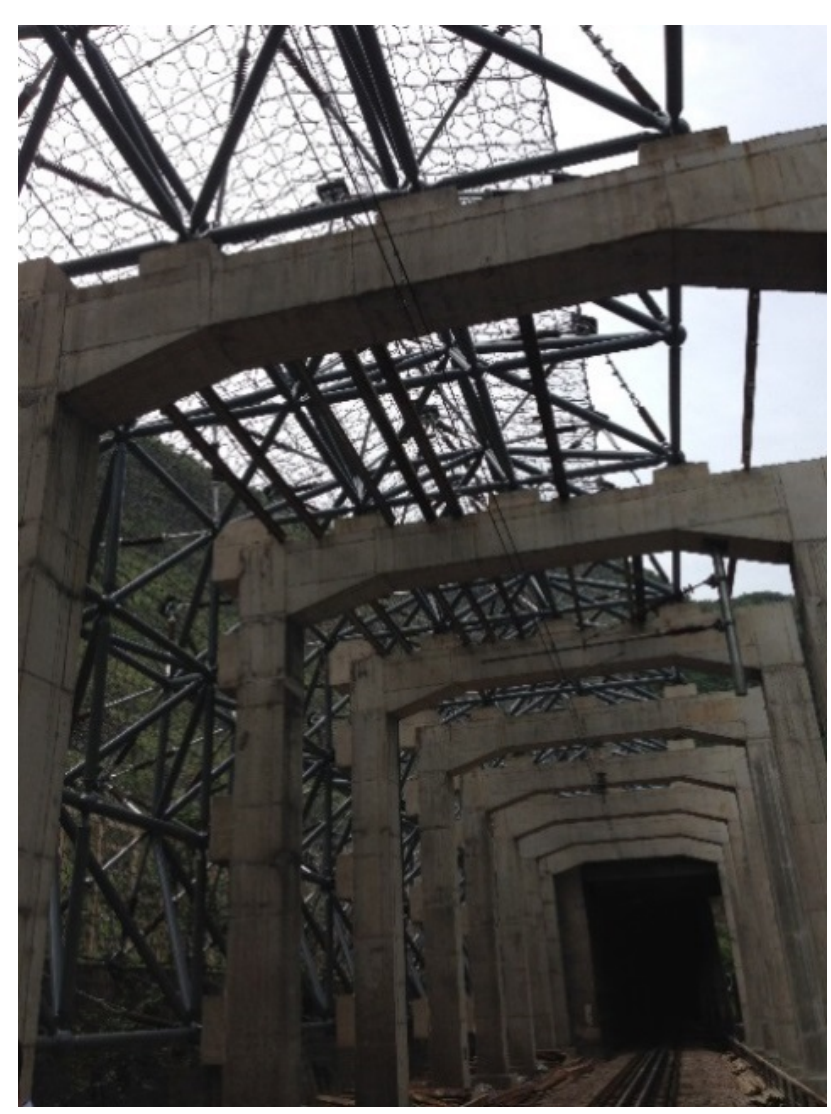

Figure 2. Photo of the finalized structure

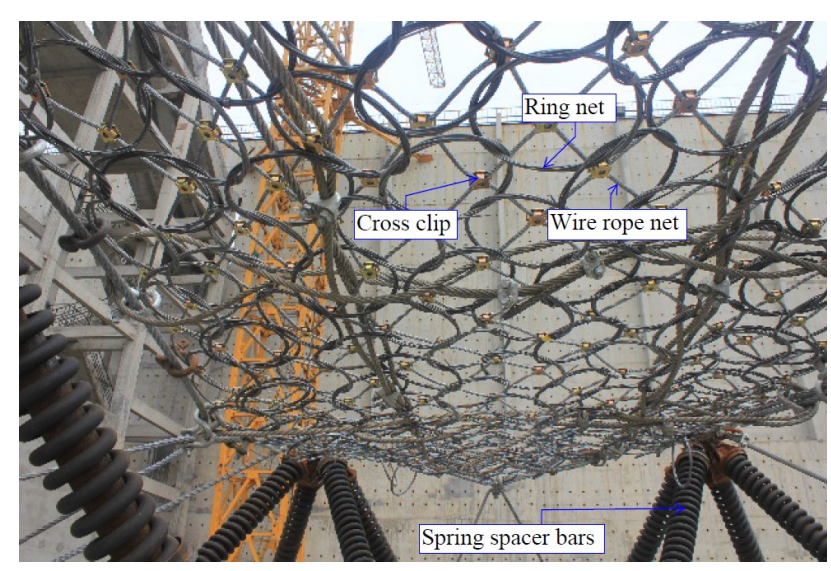

Figure 3. Details of the flexible net

The steel tube truss is built with tubes of $108 \mathrm{~mm}$ in diameterand $10 \mathrm{~mm}$ in thickness. All members of the truss are held together by bolt sphere joints. The shed consists of a total of eight reinforced concrete portal frames which lines along the railway line extending $54.0 \mathrm{~m}$. Each frame is $9.0 \mathrm{~m}$ in width and $8.8 \mathrm{~m}$ in height from rail top to the girder surface and designed under the guideline TB10003-2005 [13]. The girder and columns in each frame have the same rectangular cross section $(800 \mathrm{~mm} \times 800 \mathrm{~mm})$. The compressive-strength of the concrete is 26.9 $\mathrm{MPa}$ and HRB335 steel reinforcement bars are used.

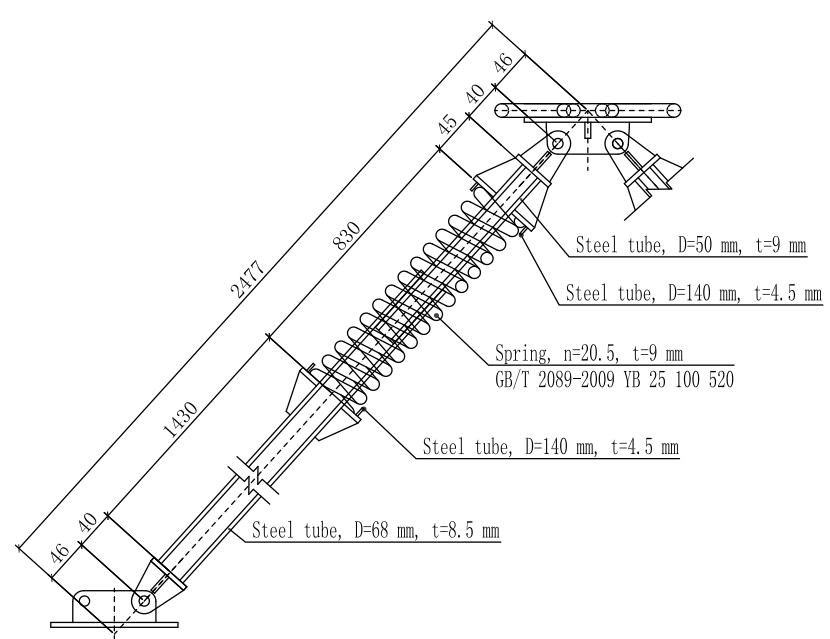

Figure 4. Constructional details of the spring spacer bar

The flexible rock-shed can be applied to the rock fall protection in the existing railway lines for its convenience of construction, easy maintenance, and adaptability to geological conditions. Since the concrete roof and cushion layers of conventional rock-shed are substituted by the flexible structure, the deadweight of the flexible rock-shed can be reduced significantly, and thus the component sections and embedded depth of foundation. It is estimated that the cost of flexible rock-shed, compared to the conventional rock-shed, will be reduced by $12 \%$ [14]. It should be noted that the diameter of the ring net reaches $300 \mathrm{~mm}$ and the mesh size of the wire rope net is $500 \mathrm{~mm} \times 500 \mathrm{~mm}$ as mentioned above. Obvious hollows exist in the flexible rock-shed, which means this proposed flexible rock-shed can be used to effectively prevent the falling rocks with relatively large diameters. When small rocks fall, they may pass through the holes in the rock-shed, and fine net meshes might be needed in this case.

\section{Experimental overview}

The upper cushioning structure of the shed plays the most important role in energy buffering and dissipating, its mechanical behavior under impact load is, however, not clear. To examine the 
effectiveness of the proposed flexible rock-shed to prevent the falling rocks, a series of experimental studies are carried out. The testing procedure is designed with reference to those of flexible barriers and concrete rock-sheds as defined in the corresponding guidelines $[15,16]$.

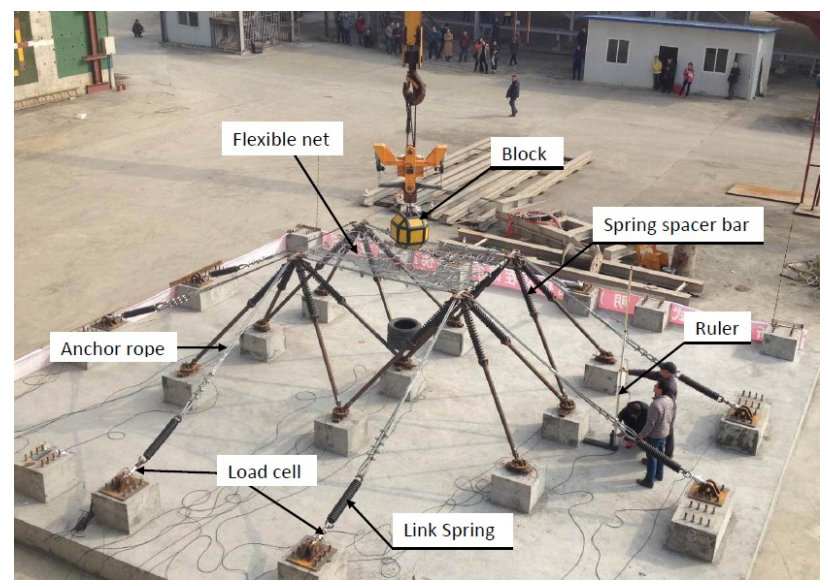

Figure 5. Experiment set-up.

As it can be seen in Figs 1 and 2, the flexible rockshed consists of a large number of standard structural units. Moreover, it is too expensive to build a full scale model for the whole structure of the shed, only part of the rock-shed was taken out and constructed to carry out the tests. However, it is worthy to mention that the scale of the considered part is $1: 1$ of the original structure. Fig. 5 shows the experimental set-up. The overall size of the flexible nets is $3000 \mathrm{~mm} \times 2000 \mathrm{~mm}$, and 16 spring spacer bars, 8 anchor ropes and 8 link springs were constructed. The springs connected to the support ropes are identical to those used for spring spacer bars with average stiffness of $432 \mathrm{kN} / \mathrm{m}$ and standard deviation of $2.23 \mathrm{kN} / \mathrm{m}$.

The impact test is conducted by freely dropping a block of $340 \mathrm{~kg}$ onto the center of the flexible net with a speed of $17.15 \mathrm{~m} / \mathrm{s}$. The falling weight is a 24 surface body cutting from a cube to approach a sphere, which is covered by thick steel plate and infilled with concrete. The mass is controlled by the infilled concrete. In order to gain the exact initial kinetic energy of $50 \mathrm{~kJ}$, the weight is lifted to an elevation of $15 \mathrm{~m}$ above the flexible nets by a crane. No destructive test is carried out. A remote control apparatus is designed and installed to the crane hook so that the block stays in static at the moment of releasing. To ensure that the block is released freely onto the center of the flexible net, a plumb line is used to determine the impact position.

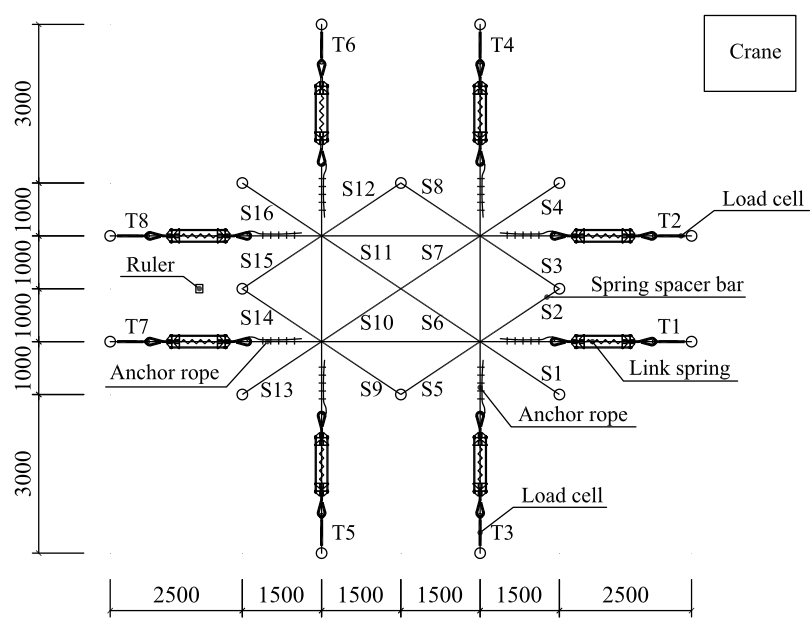

Figure 6. Testing system and layout of measuring points

The testing system and layout of measuring points are shown in Fig. 6. The dynamic strain in each spring spacer bar is measured by two strain gauges arranged symmetrically on its surface along the axial direction. Altogether, 16 sets of measuring points were set up and numbered in sequence from S1 to S16. A total of eight load cells which can compensate the thermal zero shifts, numbered sequentially from $\mathrm{T} 1$ to $\mathrm{T} 8$, were used to measure the tensile forces acting on the anchor ropes. Both strain and cable force data were collected by two dynamic data recorders (DEWE800, 16 channels) and with the same sampling rate of $10 \mathrm{kHz}$.

Two high-speed cameras (OLYMPUS, 1000 frames per second) were used to record the impact process from orthogonal viewpoints. The cameras were equipped with $3 \mathrm{D}$ motion analysis software which can calculate the displacement of the structure automatically.

\section{Numerical simulation}

Numerical simulations following the test are performed by using the explicit finite element code ANSYS/LS-DYNA, version 970. ROCCO rings, wire meshes, spring spacer bars, support ropes, anchor ropes and link springs are modelled in detail. The parameters of all the components are identical to those used in the experiment such that numerical results can reproduce the measured structural 
behavior as well as possible (Fig. 7). The material parameters are tabulated in Table 1.

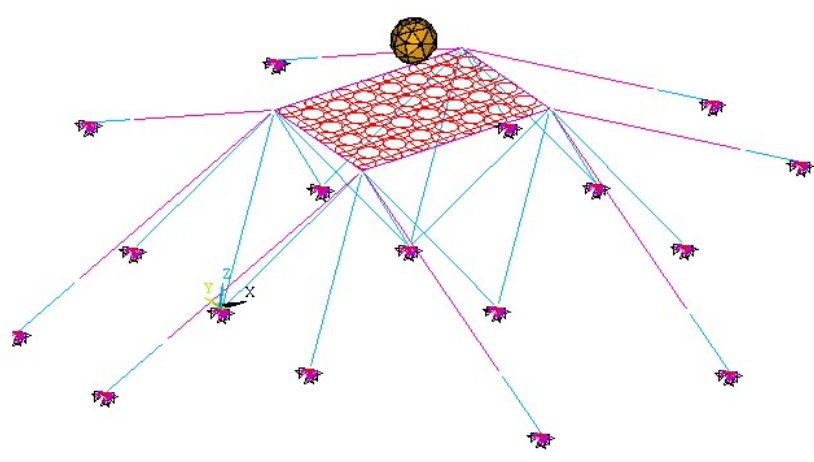

Figure 7. Numerical model of the shed unit

LINK167 element is used to simulate ROCCO rings, wire meshes, and support ropes respectively to ensure no force will develop in compression. COMBI165 element is applied to simulate spring spacer bars. The block is modelled as rigid body by defining rigid material (EDMP, RIGID) for SOLID164 element.

The ring net is modeled by generating finite element model for each of the ROCCO rings which remain tangent to each other and share the same node at the point of tangency. Each ring is reduced slightly in diameter due to the dimension reduction when linked together. Thus, the total number of the rings coincides with that of the tested structure. Also, the cross clip connection of wire rope net is modelled by sharing the same nodes at wire rope crossings. All nodes on the support ropes are assumed to be perfectly bonded with the ring net or the wire rope net where they are connected by sewing ropes to each other. The upper ends of the spring spacer bars are bounded with that of the support ropes; whereas the nodes on the other sides are hinged to ground. Displacement of the steel tube truss and reinforced concrete frames under impact is far less than that of the cushioning structure. Therefore, both are ignored from the analysis model.

Table 1. Material properties for analysis

\begin{tabular}{|l|c|c|c|c|c|}
\hline \multirow{2}{*}{ Member } & Young's modulus & Density & Yield strength & Poisson's ratio & Ultimate strain \\
\cline { 2 - 6 } & $\mathrm{MPa}$ & $\mathrm{kg} / \mathrm{m}^{3}$ & $\mathrm{MPa}$ & & $\mu \varepsilon$ \\
\hline Support rope & $1.10 \times 10^{5}$ & 7850 & 1850 & 0.3 & 0.03 \\
\hline Wire rope net & $1.10 \times 10^{5}$ & 7850 & 1850 & 0.3 & 0.03 \\
\hline Ring net & $1.77 \times 10^{5}$ & 7850 & 1770 & 0.3 & 0.05 \\
\hline Spring spacer bar & $2.06 \times 10^{5}$ & 7850 & 345 & 0.3 & --- \\
\hline
\end{tabular}

Note: the design breaking forces of support rope and wire rope net are $662 \mathrm{kN}$ and $130 \mathrm{kN}$ respectively

When loaded by the falling weight, the spring spacer bars are supposed to be in elastic state and elastic material model is applied accordingly; the support ropes, wire rope net and ring net are likely to fail and plastic kinematic material model is applied. The strain rate effect is considered by using the Cowper-Symonds model, in which the yield stress can be calculated as

$$
\sigma_{y}=\left[1+(\dot{\varepsilon} / C)^{1 / P}\right] \cdot\left(\sigma_{0}+\beta E_{P} \varepsilon_{P}^{e f f}\right)
$$

where $\sigma_{y}=$ yield stress considering the effect of strain rate; $\sigma_{0}=$ initial yield stress; $\dot{\varepsilon}=$ strain rate; $=$ $\varepsilon_{P}^{e f f}=$ effective plastic strain; $\beta=$ hardening parameter ( 0 for Kinematic hardening); $C, P=$ parameter of Cowper Symonds model, 40, 5 respectively for steel; $E_{P}=$ plastic hardening modulus, which can be calculated as

$$
E_{P}=\frac{E_{\mathrm{tan}} E}{E-E_{\tan }}
$$

where $E$ and $E_{\text {tan }}$ are elastic modulus and tangent modulus respectively.

The equivalent cross section areas of $102.00 \mathrm{~mm}^{2}$ and $357.96 \mathrm{~mm}^{2}$ are employed for the wire rope net and support ropes respectively. Since the ROCCO rings are manufactured by coiled a steel wire, the equivalent radius of the cross section can be calculated as $[17,18]$

$$
r_{1}=n^{1 / 3} r
$$

where $r_{1}=$ the equivalent radius; $r=$ radius of the cross section of $n$ wires. The equivalent cross section area of the ROCCO rings is $25.87 \mathrm{~mm}^{2}$. 
Neglecting the influence of gravity acceleration, a spherical block of $340 \mathrm{~kg}$ is released from a $1.00 \mathrm{~m}$ above the center of the flexible net with an initial speed of $17.15 \mathrm{~m} / \mathrm{sec}$ to simulate a loading of $50 \mathrm{~kJ}$ as mentioned above. The impact force is numerically surcharged against the analysis model due to adding the predetermined impact velocity to all nodes of the falling block, which is set on the surface of the flexible net. The numerical simulation starts from $0.0 \mathrm{sec}$ and lasted for $2.5 \mathrm{sec}$ with a time increment equal to $0.005 \mathrm{sec}$ which is determined based on the Courant stability condition [19]. To consider the interaction of different parts in the explicit dynamics analysis, nodes-to-surface contact (NTS) is specified between the block and flexible net with the viscous friction coefficient of 0.8 .

\section{Results and discussions}

\subsection{Numerical simulation results}

Several numerical results have been computed on the analyzed structure. Only those concerning the experiment measurements are presented in this paper (i) impact time interval, (ii) maximum deflection of the flexible net, (iii) tensile forces of anchor ropes and (iv) axial strains in spring spacer bars, as summarized in the Table 2.

On the basis of analysis results, it is possible for the flexible rock-shed to stand the impact of a block with kinetic energy of $50 \mathrm{~kJ}$ and no rupture of the flexible net and spring spacer bars has been identified. The impact time interval (ITI), time for the flexible net to buffer the impact of the block completely, is $0.1000 \mathrm{sec}$, which is defined as the time lapse between the first contact of the block with the flexible net and that instant when the block falls to the lowest point.

The maximum deflection of the flexible net has reached $1454 \mathrm{~mm}$ which is less than the $2000 \mathrm{~mm}$ reserved for the net to keep distance enough from the top chords of the truss. When the flexible structure is loaded by the weight, because of the geometric nonlinear effect, its internal force will undergo a series of redistribution according to how it deforms. The flexible net in longitudinal direction (with longer side length) acquires much more flexibility than that in transverse direction (with shorter side length). As a result, the longitudinal anchor ropes as well as the support ropes bear much more cable force than those of transverse, as shown in Fig. 8. The maximum cable force calculated is $33.45 \mathrm{kN}$ which is far less than its breaking force of $662 \mathrm{kN}$. But the diameters of the ropes keep unchanged to withstand accidental impact with kinetic energy over $50 \mathrm{~kJ}$.

From the strain history curves shown in Fig. 9, the maximum strain in the spring spacer bars is $-146 \mu \varepsilon$. The maximum axial force in the bars can be calculated as $-47.74 \mathrm{kN}$ (in compression and elastic) based on the cross-sectional area and elastic modulus of the steel tubes. Accordingly, the reaction force reaches the maximum of $217.64 \mathrm{kN}$ at the middle support. The reasonable stiffness coefficient of the springs should be somewhere between $300 \mathrm{kN} / \mathrm{m}$ to $500 \mathrm{kN} / \mathrm{m}$ according to the results of a parametric study. Due to the lack of measured data on the damping of the flexible net, contact damping is hard to define for the model. Consequently, it results in random oscillation of the cable force history curves after the block bounced back from the net.

\subsection{Experimental results and verification}

It is seen that the experimental model is capable of withstanding the impact of the falling block successfully, and no rupture of the structural elements has been observed. When subjected to the impact, both numerical and experimental models share the same characteristics of deformation. The impact time interval and the maximum deformation of the flexible net can be calculated from the tested data. Moreover, the tensile forces acting on anchor ropes and the axial strains of spring spacer bars were recorded. A comparison between the numerical results and experimental data is carried out afterwards in the Table 2.

The experiment data show an acceptable agreement with the computed results. The maximum deflection measured is $1680 \mathrm{~mm}$ and $16 \%$ larger than the calculated value, but for less time. Still is the deflection within the safe distance to the truss. A number of reasons can be seen for the faster deflection of the experimental model. Due to gravity, the sag of the support ropes and the flexible net have deviated from those in the numerical model in which the elements remain completely straight. Meanwhile, the initial connection between each member is not tight enough, which again differs from the fixed connections in the numerical model. 
As a result, the structure must first complete a certain amount of deformation before each member becomes completely loaded. Moreover, by idealizing the ring net as a group of rings being tangent to each other, the theoretical dimension of the flexible net becomes smaller than the actual size and its theoretical stiffness greater than the actual stiffness.

Fig. 8 shows the cable force time history diagrams at $\mathrm{T} 2$ to $\mathrm{T} 5, \mathrm{~T} 7$ and $\mathrm{T} 8$ respectively as recorded by the load cells. Unfortunately, $\mathrm{T} 1$ and $\mathrm{T} 6$ are damaged for unknown reasons. In the figure, tested diagrams are displayed in real lines, otherwise in broken lines. The start time points of the tested diagrams differ from those from numerical simulation. So the origin time of the tested diagrams is aligned with that of the numerical ones by assuming that their peak values occur at the same time.

Table 2. Comparison of numerical and experimental results

\begin{tabular}{|c|c|c|c|c|}
\hline \multicolumn{2}{|c|}{ Classification } & Test 1 & Numerical (2) & 1//2) \\
\hline \multirow{2}{*}{ Rock fall to the lowest point } & Deflection /mm & 1680 & 1454 & 1.16 \\
\cline { 2 - 5 } & ITI/sec & 0.0984 & 0.1000 & 0.98 \\
\hline \multirow{4}{*}{$\begin{array}{c}\text { Tensile force extremum } / \mathrm{kN} \\
\text { (Anchor rope) }\end{array}$} & $\mathrm{T} 2$ & 26.38 & 28.93 & 0.91 \\
\cline { 2 - 5 } & $\mathrm{T} 3$ & 2.59 & 1.15 & 2.24 \\
\cline { 2 - 5 } & $\mathrm{T} 4$ & 2.61 & 0.65 & 4.03 \\
\cline { 2 - 5 } & $\mathrm{T} 5$ & 2.72 & 0.68 & 3.97 \\
\cline { 2 - 5 } & $\mathrm{T} 7$ & 28.47 & 33.45 & 0.85 \\
\hline \multirow{3}{*}{$\begin{array}{c}\text { Axial strain extremum / } \mu \varepsilon \\
\text { (Spring spacer bar) }\end{array}$} & $\mathrm{T} 8$ & 26.3 & 27.68 & 0.95 \\
\cline { 2 - 5 } & $\mathrm{S} 1$ & 45.27 & 52.48 & 0.86 \\
\cline { 2 - 5 } & $\mathrm{S} 2$ & -26.13 & -24.70 & 1.06 \\
\cline { 2 - 5 } & $\mathrm{S} 5$ & -77.98 & -72.78 & 1.07 \\
\hline
\end{tabular}

Note: the design breaking forces of the support rope and wire rope net are $662 \mathrm{kN}$ and $130 \mathrm{kN}$ respectively.

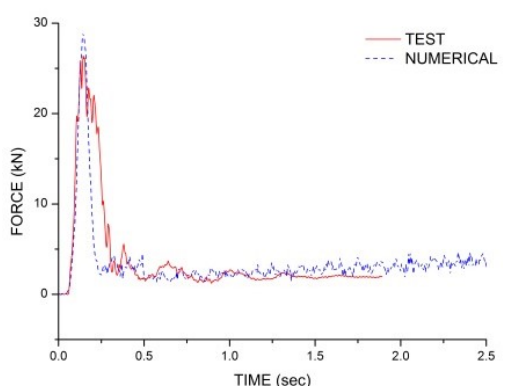

(a)

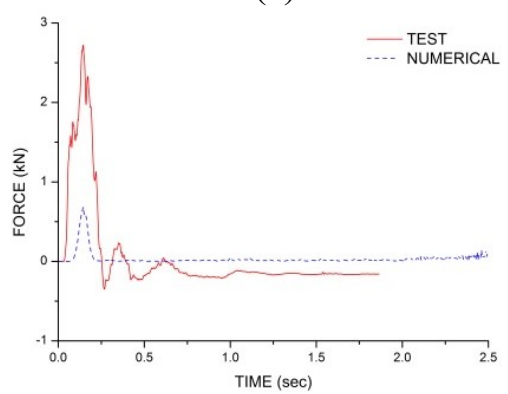

(d)

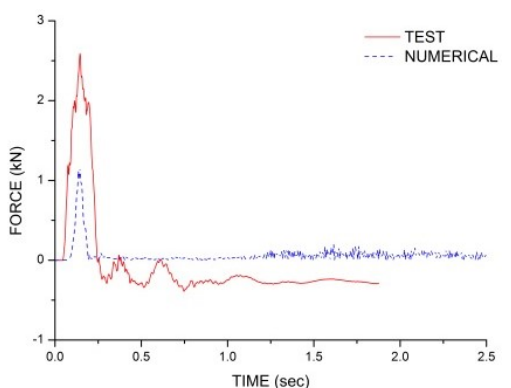

(b)

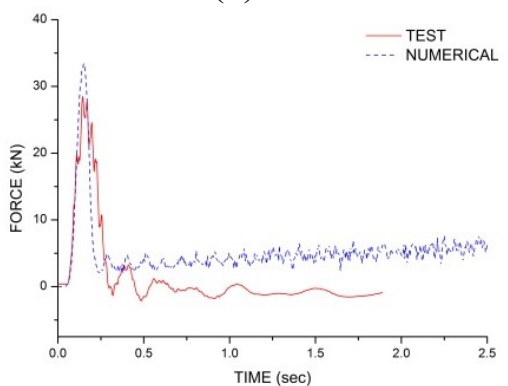

(e)

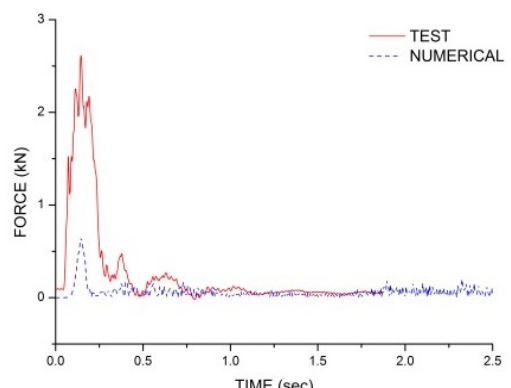

(c)

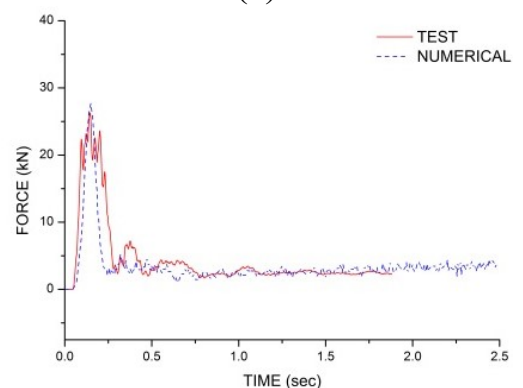

(f)

Figure 8. The numerical and experimental cable force. (a) Time-cable force diagram of T2; (b) time-cable force diagram of T3; (c) time-cable force diagram of T4; (d) time-cable force diagram of T5; (e) time-cable force diagram of T7; (f) time-cable force diagram of T8 
From the peak values of tested cable forces, it is seen that the tensile forces in longitudinal anchor ropes are 10.24 times larger in average than the transverse ropes. This is in good coincidence with the numerical results, and this further illustrates that, for a structure with strong geometric nonlinearity like the flexible net, the elements with more flexibility bear more load that the stiffer ones. The calculated cable forces in longitudinal direction agree well with measurements with extreme deviation of $15 \%$ whereas, in transverse direction, they appear far less than measurements indicating that the numerical model and the experimental model are different in some aspects. Since the wind load makes the hook swaying slightly, the block can hardly be dropped onto the center of the net. Due to the measurement error, manufacturing errors and other reasons, there still exists deviation between actual measured and computed diagrams.

Fig. 9 shows the strain history diagrams at S1, S2, S5, S6 respectively as recorded by the strain gauges for the spring spacer bars. Similar patterns can be

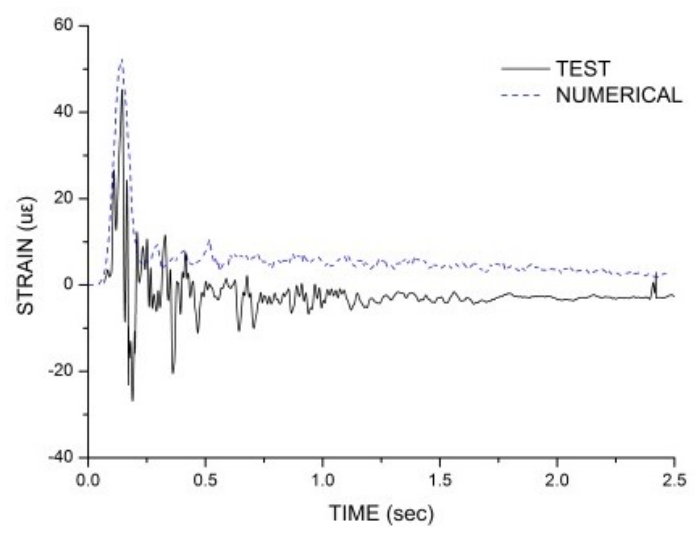

(a)

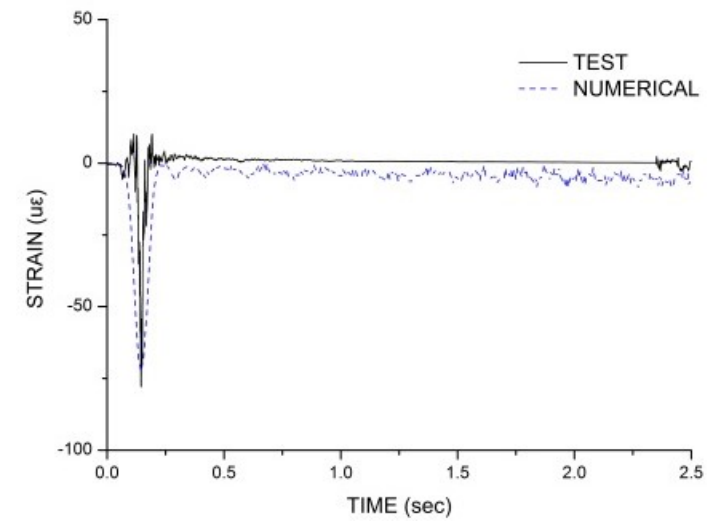

(c) observed for the rest of the structure by symmetry. Again, the origin time of the tested diagrams is aligned with that of the numerical ones by the same method. The strain of each spring spacer bar is the average value of the two strain gauges. From this figure, it is observed that the calculated strain diagrams agree well with measurements with extreme deviation of only $11 \%$. When the block falls to its lowest point, S1 reaches an extreme of $45.27 \mu \varepsilon$, whereas the rest reached the extreme of compression. The maximum strain tested is -129.73 $\mu \varepsilon$ in $\mathrm{S} 6$ corresponding to a maximum axial force of $-42.42 \mathrm{kN}$ (being in compression and elastic). In default of the measured value, an estimation of $193.38 \mathrm{kN}$ has been made for the maximum reaction force according to the axial forces in the spring spacer bars with the influence of the rotation considered. This is very close to the calculated value which was applied to the design of the steel tube truss and the reinforced concrete frames. In this way, the substructures are guaranteed to behave in their elastic range.

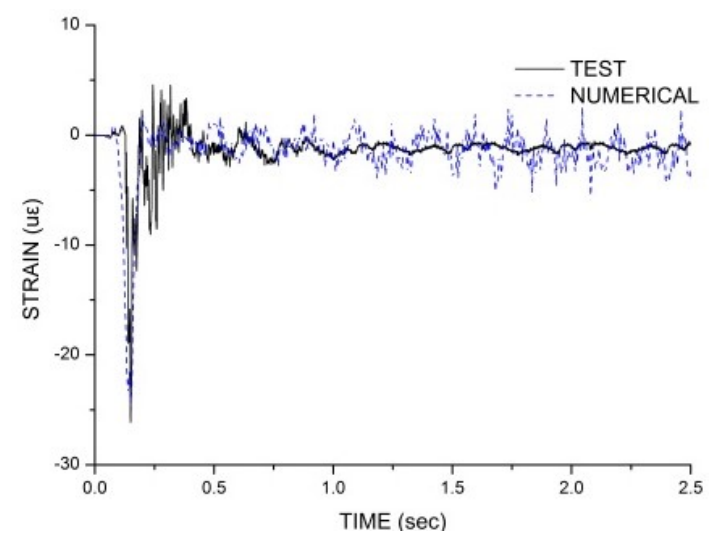

(b)

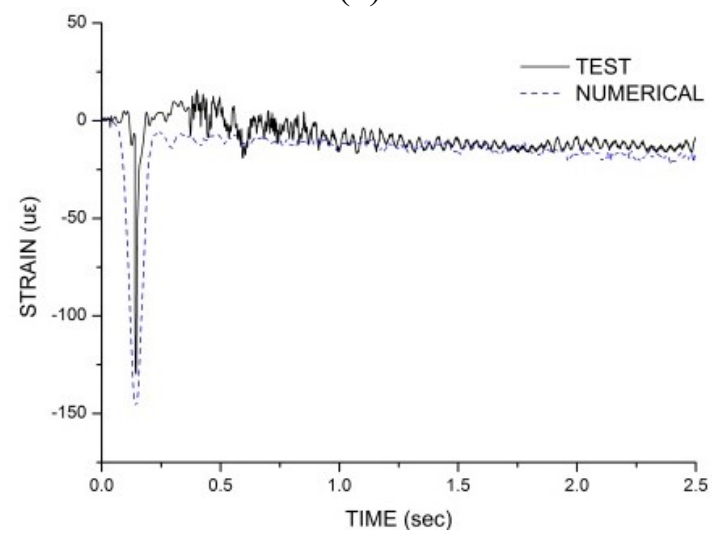

(d)

Figure 9. The numerical and experimental strain of spring spacer bars. (a) Time-strain diagram of S1; (b) time-strain diagram of S2; (c) time-strain diagram of S5; (d) time-strain diagram of S6 
After reaching the lowest point, the block, as well as the structure, began to rebound. In the process, the potential energy was released. At last, the block flied off the rock-shed with attenuated kinetic energy. Significant residual deformation was found in the flexible net after the impact of the block, which can hardly be predicted in numerical simulation and the net hanged down about $860 \mathrm{~mm}$. In the experiment, the ring net, the wire rope net, and sawing ropes rendered no fracture. Single rings in the ring nets did not deform much. In addition, no sliding was observed for the cross clips. All spring spacer bars rebounded automatically back into the original position. The support ropes were highly loosed and could be renovated after being tensioned again.

\section{Conclusion}

By mixing flexible barriers and structural rocksheds, a new concept of flexible rock-shed is presented for protection of railway from the rock fall. Its protection mode, however, appears different from the flexible barriers and the conventional reinforced concrete rock-sheds. In normal, the impact energy is buffered directly by the large deflection of the flexible net and by the actuation of spring spacer bars while the steel tube truss and the portable frames behave in their elastic range. Coherent experimental and numerical studies are carried out on the dynamic behavior of the flexible rock-shed under rock fall impacts. Some conclusions can be drawn.

The shed is capable of withstanding impact energy up to $50 \mathrm{~kJ}$ without rupture of the flexible net and can be put into service immediately by tensioning the support ropes again. When impacted, both the deflection of the flexible net and internal force response suffice the requirements of design. The falling weight has kept a safe distance from the truss underneath during the whole process. The good agreement of the rather complex experimental and numerical results can assess the ability of the finite element model to reproduce the dynamic behavior. Therefore, validating the reliability of the adopted numerical approach and giving confidence to the use of such models as design tools. However, the approach claims complicate computation which is not convenient for engineering application. There still needs to do further research on the simplified design methods.
For a flexible net, how the impact force is distributed among the components depends solely on their contribution to the structural flexibility. Hence, each component is expected to be carefully designed so that the flexibility comes to the point of uniform distribution and then an optimum distribution of impact force becomes possible.

For energy levels of rock fall that happen in normal conditions, the flexible rock-shed relies much on the elastic deformation of the flexible nets for energy absorption. If the level exceeds the design value, the kinetic energy of rock fall can be absorbed by the elastic-plastic deformation and damaged components need to be replaced afterwards. When it comes to low intensity shocks which are more frequent, the flexible rock-shed has the advantage of technology over conventional reinforced concrete rock-sheds; otherwise, for high energy impacts, the conventional rock-sheds are preferred but cost more.

\section{Acknowledgements}

The present research is funded by the State Key Laboratory Breeding Base of Mountain Bridge and Tunnel Engineering Funding (Chongqing Jiaotong University, Grant No. CQSLBF-Y13-9). Any opinions, findings, conclusions, or recommendations expressed in this paper are those of the authors and do not necessarily reflect those of the sponsor.

\section{References}

[1] Sara, G. K., Thomas V., Norimitsu K.: Numerical simulation of rockfall protection galleries, ETH, Zürich, 2011.

[2] Delhomme, F., Mommessin, M., Mougin, J. P., Perrotin, P.: Damage mechanisms of a reinforced concrete rock-shed slab impacted by blocks, Journal of Structural Engineering, 133 (2007), 10, 1426-1433.

[3] Ikeda, K., Kishi, N., Kawase, R., Konno, H., Nakano, O.: A practical design procedure of three-layered absorbing system. Proceedings of the Joint Japan-Swiss Scientific Seminar, Department of Civil Engineering, Kanazawa University, Japan, 1999, 113-119.

[4] Mougin, J. P., Perrotin, P., Mommessin, M., Tonnelo, J., Agbossou, A.: Rock fall impact on reinforced concrete slab: an experimental approach, International Journal of Impact Engineering, 31 (2005), 169-183. 
[5] Delhomme, F., Mommessin, M., Mougin, J. P., Perrotin, P.: Behavior of a structurally dissipating rock-shed: experimental analysis and study of punching effects, International Journal of Solids and Structures, 42 (2005), 4204-4219.

[6] Delhomme, F., Mommessin, M., Mougin, J. P., Perrotin, P.: Simulation of a block impacting a reinforced concrete slab with a finite element model and a mass-spring system, Engineering Structures, 29 (2007), 2844-2852.

[7] Wang, M., Shi, S. Q., Yang, Y. K.: Experimental study on a new type flexible rockshed under impact of rockfall, China Civil Engineering Journal, 46 (2013), 9, 131-138.

[8] Wang, M., Shi, S. Q., Yang, Y. K.: Numerical simulation of a flexible rock shed under the impact of a rockfall, Engineering Mechanics, 31 (2014), 5, 151-157.

[9] Shi, S. Q., Wang, M., Peng, X. Q., Yang, Y. K.: A new-type flexible rock-shed under the impact of rock block: initial experimental insights, Natural Hazards and Earth System Science, 13 (2013), 12, 3329-3338.

[10] Liu, C. Q., Chen, L. Y., Chen, C., Li, J. J., Zhao, S. C.: Application of flexible shed-tunnel structure to rock-fall hazard prevention, Journal of Southwest Jiaotong University, 50 (2015), 1, 110-117.

[11] Volkwein, A.: Numerical simulation of flexible rockfall protection systems, Proc. of the ASCE International Conference on Computing in Civil Engineering, Cancun, Mexico, 2005, 1-11.

[12] National Standard of the People's Republic of China: Cylindrical Coiled Compression Spring Dimensions and Parameters (GB/T 20892009), China Standard Press, Beijing, 2009.

[13] National Standard of the People's Republic of China: Code for Design on Tunnel of Railway (TB10003-2005 J 449-2005), China Standard Press, Beijing, 2005.

[14] Bai, Y., Yang, J. R., Su, H. X., Yang, X. D.: Theoretical and experimental study of flexible rock shed, Earthquake Resistant Research Institute of Kunming University of Science and Technology, Kunming, 2015.

[15] EOTA: ETAG 027 - guideline for European technical approval of falling rock protection kits, Tech. rep., European Organization for Technical Approvals, Brussels, 2008.
[16] Gerber, W.: Guideline for the approval of rockfall protection kits, Swiss Agency for the Environment, Forests and Landscape (SAEFL) and the Swiss Federal Research Institute WSL, Berne, 2001.

[17] Wang, M., Shi, S. Q., Kang, J. G.: Numerical and theoretical analysis of dissipation energy capacity of ring net impacted by rockfall, Journal of Vibration and Shock, 30 (2011), 3, 10-13, 21.

[18] Wang, M., Shi, S. Q., Yang, Y. K.: Comparative analysis for capacity of energy dissipation of a ring net with two different connection forms, Journal of Vibration and Shock, 31 (2012), 2, 55-61.

[19] Chen, Y. S., Wu, B., Pan, T. L.: A novel sectional constitutive model for beam-column element, Engineering Review, 36 (2016), 1, 4152. 